nidus in the urinary tract. Calculi formed in and passed down from the kidney are very common; the pain which accompanies the descent of the calculus is very severe and distressing. After much experience of this affection, I find the best plan of treatment is by hot hip baths, copious enemata of hot water, mustard or cupping to loins, free action of purgatives to clear the colon, and then the free exhibition of morphia, with which I have combined belladonna with excellent effect. Stones occasionally stick in the urethra, and give rise to much additional pain and anxiety. Considering the frequency with which I have had to treat nephralgia calculosa, the presence of stone in the bladder is rare.

Provincial Hospital, Port Elizabeth, South Africa, 1871.

\section{A SAFETY HYPODERMIC SYRINGE.}

By W. R. GOWERS, M.D.

RetuCtance is often felt to trust the ordinary hypodermic syringe in the hands of a patient or a nurse, on account of the facility with which an accidental overdose may be administered. This danger may be completely avoided by a slight addition to the ordinary syringe which Mr. Hawksley, of Blenheim-street, has made for me. It consists of a stop placed upon the piston-rod within the barrel, and moving up and down the rod by a screw. This stop prevents the piston from being drawn up beyond a certain distance. Thus the maximum capacity of the syringe may be fixed at any desired quantity, and nıay be altered by unscrewing the collar of the syringe, drawing out the piston-rod, and altering the position of the stop. The syringe being thus set for a given dose, not more than that dose can, by any accident, be given at one injection.

Queen Anne-street, Jan. 1872.

\section{d. afthror}

$$
O F^{2}
$$

\section{H O S PITAL PRACTICE,}

\section{BRITISH AND FOREIGN.}

Nulla autem est alia pro certo noscendi via, nisi quamplurimas et morborum et dissectionum historias, tum aliorum, tum proprias sollectas habere, et inter se comparare.-MorgagrX De Sed. et Caus. MTorb., lib. iv. Procemium.

\section{WESTMINSTER HOSPITAL.}

ESCAPE OF A TRACHEOTOMY-TUBE INTO THE TRACHEA, OWING TO EROSION OF THE JUNCTION OF THE TUBE AND SHIELD ; REMOVAL BY ENLARGING THE ORIGINAL OPENING.

\section{(Under the care of Mr. Holthouse.)}

$\mathrm{WE}_{\mathrm{E}}$ are glad to lay before our readers (from notes by $\mathbf{M r}$. R. C. Pritchard, assistant house-surgeon) the full particulars of the following case, which forms an interesting sequel to the similar one read by Dr. John Ogle at a late meeting of the Medico-Chirurgical Society. We particularly recommend instrument makers to profit by the lesson contained in these two cases, and to adopt the hint thrown out during the debate on Dr. Ogle's case, of making the tracheotomy tube and its shield "one and indivisible."

R. W- , a man aged forty-five, had laryngotomy performed by Dr. Morell Mackenzie on February 14th, 1868, for dysphagia and dyspncea. He wore the same tracheotomy tube till the 16 th November, 1871, when, whilst taking his tea, he was suddenly seized with a violent fit of coughing; and on putting his hand to his throat he found slight bleeding. The tube had broken through at its junction with the shield and fallen into the trachea. He immediately went to the Westminster Hospital.

On admission there was at first urgent dyspnœa; the countenance was congested and anxious; but on lying down the difficulty of breathing disappeared and respiration was easy. Mr. Holthouse, having been sent for and shown the shield, auscultated the chest, when the respiratory murmur was found to be scarcely appreciable on the left side, but rather exaggerated on the right, though no detectable dif-

\section{ference was observed between the movements of the two} sides of the chest, and percussion was clear on both sides.

The opening in the crico-thyroid membrane was enlarged to the extent of one inch or more in the following manner:The skin was first divided in the middle line with a scalpel; then one blade of a strong blunt-pointed pair of scissors was introduced through the opening in the larynx, and the cricoid cartilage and two or three of the upper rings of the trachea were divided by successive strokes of the scissors, though with some difficulty, owing to their being ossified. There was but little bleeding; and, after it had ceased, a bullet-probe was passed downwards through the wound till it touched the canula, which was found lodged just above the left bronchus. $A$ long pair of forceps was then introduced, but, as it failed to grasp the tube, and excited violent coughing, it was at once withdrawn. The patient was then placed prone, and the lower part of the trunk being elevated, the back was sharply slapped. This dislodged the tube, and brought it up to the opening in the trachea. After some difficulty (owing to the ossification before alluded to) the sides of the wound were forcibly separated by means of retractors, and the tube was then grasped by a pair of polypus forceps and withdrawn.

The patient had no unfuvourable symptoms, and, having been supplied with a new tube, was discharged after a fortnight's sojourn in the hospital.

\section{GUY'S HOSPITAL.}

IN our Mirror of last week will be found a few general observations by Dr. Wilks on the employment of alcohol as a medicine. We this week supplement those remarks by a rather more detailed account of the views of that physician on this important subject. For our own part, we would much rather take Dr. Wilks's " mistura alcoholica" than the fiery, astringent, adulterated trash which is of ten honoured by the name of "wine" in many of our hospital dietaries.

The Administration of Alcohol.-Dr. Wilks, for the purpose of watching more closely the effects of alcohol on the system, has for many years prescribed a medicine which he calls "mistura alcoholica," composed of rectified spirit, tincture of cardamoms, and water, to be given at intervals during the day. But it is only in a particular class of cases that it is applicable. For the various ordinary acute and chronic disorders he has used wine and brandy when he bas considered them necessary. It has been more especially in cases of atropby in children and in tuberculosis that he has used this form with the most beneficial results. He believes that he was indebted many years ago to Dr. Sutton (now of the London Hospital) for this method of administering alcohol, and he has continued to use it ever since with verv often marked success. When physician to the Royal Infirmary for Children, Dr. Wilks of ten prescribed small doses of rectified spirit, according to the above formula; but, unfortunately, there is no record of the results. He remembers one case, of a little boy who was said to have maras. mus. He lay in bed almost a skeleton, and had taken all kinds of nourishment, with cod-liver, oil in vain. He was then ordered small doses of alcohol four times a day, and rapidly improved, so that in a few weeks he was fat and strong.

Dr. Wilks says he must leave it to the physiologists to determine the action of alcohol in the system; but from the fact of its not being eliminated, and from persons growing fat who partake of it, he has never discarded Liebig's views; certain it is that wasted children often directly improve under its use.

At the present time there is a little boy, aged five years and a half, in Guy's Hospital, under Dr. Wilks's care, who is on this plan. He was admitted in an extreme state of emaciation on Oct. 25th. No disease could be found in him, and he was handed over to the sister of the ward to take charge of, as it was thought his ailments might be due merely to starvation. In spite, however, of good living, with a little wine, he did not improve, and therefore, after being in for about six weeks, on Dec. 15th he was ordered one drachm of rectified spirit four times a day. In a few days he was better. He was soon able to leave his bed, and he has been growing fatter and stronger ever since. 